\title{
REVIEW
}

\section{Rheumatoid arthritis as cardiovascular risk factor: an update}

\author{
Calin D. Popa ${ }^{1,2}$
}

\begin{abstract}
Rheumatoid arthritis (RA) patients have a $1.5-2.5$ higher chance to develop cardiovascular diseases (CVD), which in turn represent the most important cause of mortality and the most frequent comorbidity in these patients. Chronic inflammation crucially contributes to that, either as an independent risk factor or as a modulator of traditional cardiovascular (CV) risk factors, such as dyslipidemia and hypertension. The cardiovascular risk management (CVRM) is therefore essential in these patients. The implementation of it in the daily practice is quite challenging and requires a good networking between different specialists (rheumatologist, cardiologist, internist) and the general practitioners (GPs), and may get various forms of organization depending on region and locations.
\end{abstract}

Keywords: rheumatoid arthritis, inflammation, cardiovascular risk, cardiovascular diseases.

Rezumat: Pacienții cu poliartrită reumatoidă au un risc de 1,5-2,5 ori mai mare pentru a dezvolta boli cardiovasculare, care la rândul lor reprezintă principala cauză de mortalitate și principala comorbiditate la acești pacienți. Inflamația cronică contribuie într-un mod esențial la acest lucru, atât ca factor de risc independent cât și prin modularea unor factori de risc tradiționali, cum ar fi dislipidemia și hipertensiunea arterială. Din aceste considerente, managementul riscului cardiovascular devine deosebit de important pentru acești pacienți. Punerea lui în practica de zi cu zi este, însă, destul de complexă și uneori anevoioasă, având nevoie de o colaborare cât mai strânsă între diverși specialiști (reumatologi, cardiologi, internisti) și medicii de familie, cu posibilitatea realizării unor soluții variate la nivel local, regional sau național.

Cuvinte cheie: poliartrita reumatoidă, inflamație, risc cardiovascular, boli cardiovasculare.

\section{INTRODUCTION}

Rheumatoid arthritis (RA) is one of the most frequent chronic inflammatory diseases (I\% from the general population). RA is characterized by a polyarthritis that usually involves the small joints of the hands and feet, but larger joints such as the knees and hips could also be affected. Besides arthritis, other so called "extra-articular" manifestations can take place in RA, including rheumatic nodules, interstitial lung disease, subfebrile temperature or signs and symptoms related to other autoimmune disease RA can overlap with (Sjgören syndrome, vasculitis, myositis etc.).

Rheumatoid arthritis (RA) is also known to associate often with other comorbidities, mainly due to the presence of the chronic autoimmune processes. Accordingly, RA patients have a higher risk to develop various infections (parodontitis, urinary tract in- fections, gastro-enteritis, Epstein-Barr virus infection), malignancies (lymphoma's, lung cancer) and cardiovascular diseases (CVD)'. The therapy of these patients using various immunosuppressive agents may have an important impact on the risk of comorbidities, either favoring their incidence (higher chance for infections for instance) or diminishing their chance of occurrence (lower risk of CVD).

Cardiovascular diseases are the most frequent comorbidity in RA patients and the main cause of death in this group of patients as well ${ }^{2}$. From this perspective, the management of CVD in RA becomes equally important as the management of RA self and has further a crucial impact on the prognosis and quality of life of these patients. Nevertheless, it is only in the last decades that CVD in RA have received more attention leading to the development of guidelines and

\footnotetext{
Department of Rheumatology, Sint Maartenskliniek Nijmegen, Netherlands

${ }^{2}$ Department of Rheumatology, Radboudumc Nijmegen, Netherlands
}

\section{$\checkmark$ Contact address:}

Calin Popa, MD PhD, Department of Rheumatology, Sint

Maartenskliniek, Hengstdal 3, 6574 NA, Ubbergen, Netherlands.

E-mail: c.popa@maartenskliniek.nl 
recommendations in order to prevent their occurrence (cardiovascular risk management - CVRM). Despite an increasingly awareness of the increased CV risk in RA patients and the need to tackle this problem, one can also observe that the implementation of this knowledge in the daily practice is still limited and suboptimal ${ }^{3}$. This article aims to shed more light in the factors contributing to the CVD in RA patients as well as to address the CVRM in these patients, insisting on the most important barriers for its implementation in the daily practice.

\section{CARDIOVASCULAR DISEASES IN RA}

The most important types of CVD in RA patients are presented in Figure I. RA patients have a 1.5 to 2.5 higher risk to develop CVD than the age and gender matched individuals in the general population ${ }^{2}$. This increased risk is likely to be due to the presence of traditional CV risk factors as well as RA-related chronic inflammation. The total CV risk is therefore not entirely explained by traditional CV risk factors, which in turn suggests that RA acts as an independent risk factor for the development of CVD ${ }^{4}$. It has been previously indicated that RA and atherosclerosis have similar pathogenic pathways where different immune cells, adhesion molecules and pro-inflammatory cytokines play important roles. This pro-inflammatory status can accelerate the development and progression of atherosclerosis in RA patients ${ }^{5}$.

Various studies have suggested that RA patients often shown asymptomatic and/or subclinical cardiovascular diseases. Cardiac MRIs and PET-CTs in RA patients with overt CVD have indicated in almost half of the situations that these patients have cardiac fibrosis

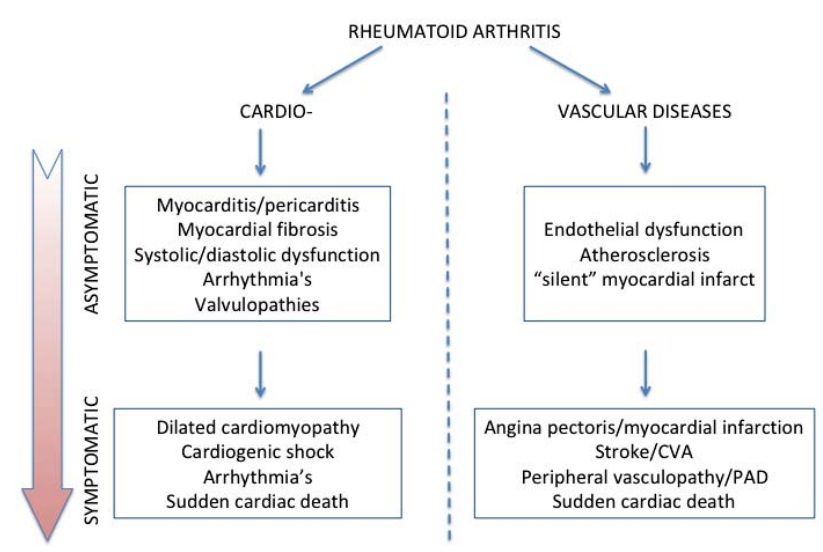

Figure I. Cardiovascular diseases in rheumatoid arthritis. and inflammation ${ }^{6}$. Moreover, a diastolic dysfunction of the left ventricle has been more often seen in RA patients, as assessed by the cardiac ultrasound examination. Finally, there is an increased prevalence of pericarditis and valvular pathology in RA patients as compared to the general population, yet these cases are much lesser than those with atherosclerosis-driven cardiac ailments ${ }^{7}$.

The subclinical modifications in the heart of patients with RA are also present in the coronary microcirculation. One third of the RA patients without a history of CVD would develop a cardiac microvascular dysfunction $^{8}$. In addition, RA patients have higher prevalence, more severe and much more locations with coronary plaques, as assessed by CT-angiography ${ }^{6}$. Of note, the chance to develop a "still" myocardial infarction is two times higher in RA than in the general population. Finally, the 30-days mortality after a myocardial infarction is increased in RA patients: 18\% in RA compared to $11 \%$ in the non-RA population?.

\section{I Chronic inflammation}

Inflammation has been previously demonstrated to play a crucial role in the development of atherosclerosis. Inflammatory markers, such as high-sensitive Creactive protein (hs-CRP) are able to predict CV risk in the general population, independent of the traditional CV risk factors. RA-driven inflammatory processes are able to trigger various pathways that contribute to the occurrence of major acute cardiovascular events (MACEs) in several patients (Figure 2). The serum concentration of CRP at diagnosis might also predict $\mathrm{CV}$ morbidity in RA. Active disease can increase the $\mathrm{CV}$ risk in RA, whereas remission and low-disease activity are associated with reduced CV risk ${ }^{10}$. Using a larger international cohort of more than 5000 RA patients, Crowson et al. shown that almost $30 \%$ of the total CV risk in RA patients could be attributed to disease-related factors ${ }^{\prime \prime}$.

Chronic inflammation contributes to and accelerates atherosclerosis in RA. Endothelial dysfunction, an early marker of atherosclerosis and a CVD predictor as well, is often indicated to be present in RA patients ${ }^{5}$. Several studies have shown that the carotid intima-media thickness (cIMT) is more often increased in RA patients as compared to age- and gender-matched individuals from the general population ${ }^{6}$. In addition, it is likely that the most of the plaques in RA presented markers of instability, which in turn is known to be associated with higher $\mathrm{CV}$ risk. Similar findings have been observed when the coronary system has been 


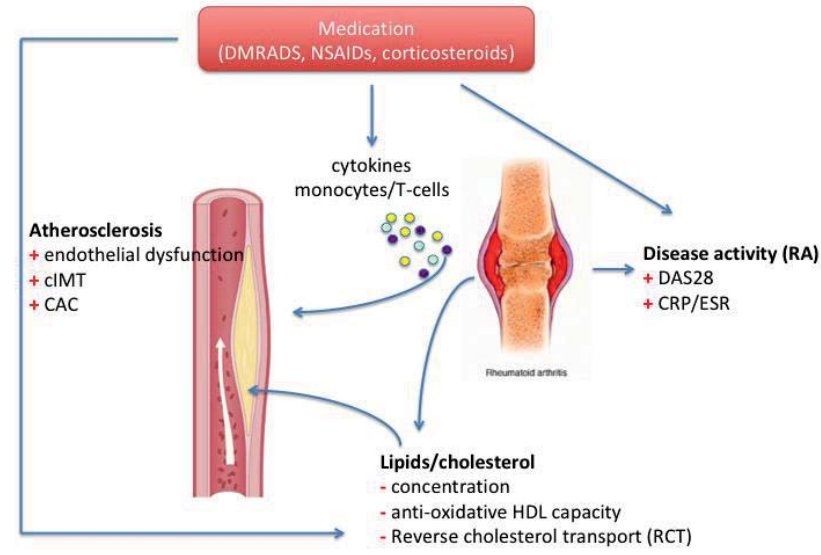

Figure 2. The relation between inflammation and cardiovascular diseases in rheumatoid arthritis. (DMARDs = disease modifying anti-rheumatic drugs; NSAIDs = non-steroidal anti-inflammatory drugs; $\mathrm{cIMT}=$ carotid intima-media thickness; $\mathrm{CAC}=$ coronary artery calcification; DAS28 $=$ disease activity score 28 ; $C R P=C$-reactive protein; $E S R=$ erythrocytes sedimentation rat; $\mathrm{HDL}=$ high-density lipoprotein; $\mathrm{RA}=$ rheumatoid arthritis).

assessed using CT-angiography. Moreover, the unstable plaques in the coronaries were often associated with high RA- disease activity ${ }^{6}$.

Finally, inflammation affects some traditional CV risk factors as well. Accordingly, insulin resistance increases when systemic inflammation rises, the metabolic syndrome and type- 2 diabetes mellitus are more often seen in RA and patients with diabetes are known to bare a low-grade inflammatory state at the adipose tissue level ${ }^{12}$. The relation between inflammation and lipoproteins is also assessed in RA patients. Consecutively, the concentration of the most lipoproteins decreases when chronic systemic inflammation increases (high disease activity) and the other way around. Of note, the low lipid levels during periods with active inflammation are associated with a higher risk to develop CVD. This phenomenon is called "the lipid paradox"'3. This has implications for the daily practice and has led to the recommendation of assessing the $\mathrm{CV}$ risk in RA patients only during the periods of low-disease activity and/or remission. Besides the concentration, the composition of various lipoproteins could be influenced by the presence of inflammation as well. Especially the HDL-cholesterol molecule changes during the periods with active inflammation ${ }^{14}$. HDL-cholesterol has a strong anti-atherogenic effect, due to the capacity of removing cholesterol from the arterial walls and transporting him to the liver (the so called reverse cholesterol transport -RCT) as well as due to its anti-oxidative capacity. Therefore, inflammation is associated not only with lower HDL- cholesterol levels but also with a diminished RCT and anti-oxidative capacity as well. These pro-atherogenic effects are luckily reversible and could be normalized when RA is efficiently treated and low disease activity and/or remission is achieved ${ }^{15}$.

\subsection{Traditional risk factors}

The development of CVD is dependent on the presence of several so-called "traditional" CV risk factors, such as age, gender, hypertension, hypercholesterolemia, diabetes, smoking, obesity and physical (in)activity. The prevalence of traditional $\mathrm{CV}$ risk factors in RA patients is often higher than in the general population $^{16}$. Nevertheless, the higher CV risk in RA cannot be explained only by the presence of these factors ${ }^{\prime \prime}$. Because RA is regarded as an independent $C V$ risk factor, similar to diabetes, the traditional CV risk factors in RA patients should get as much attention as in the case of diabetes patients. Yet, there is still a high number of RA patients in the daily practice who have a suboptimal therapy for their modifiable CV risk factors and even some who have no therapy at all, especially for dyslipidemia and hypertension ${ }^{3}$.

In a recent study done in Great-Britain, Toms et al. shown that only $41 \%$ of RA patients having an indication for therapy with statins according to their CV risk score were also treated with these drugs, leaving thus the majority of them $-59 \%$ - not treated at all ${ }^{17}$. Later on, van den Oever et al. indicated in a Dutch population that $69 \%$ of the RA patients studied had an indication to start medication (anti-hypertensive and/ or cholesterol lowering therapy); of them, $42 \%$ were treated inadequately (meaning that they did not reach the target LDL-cholesterol and the target blood pressure values) and $40 \%$ had no therapy at all ${ }^{3}$. In other words, only $18 \%$ received proper cardiovascular prevention. The authors concluded that failing to screen for the presence and the inadequate therapy of cardiovascular risk factors in RA patients would represent an important factor contributing to the increased $\mathrm{CV}$ morbidity and mortality reported in RA in the year 2020. Therefore, there is clearly more room for improvement regarding this issue.

\section{CARDIOVASCULAR RISK MANAGEMENT (CVRM)}

The European League against Rheumatism (EULAR) has published in 2017 its new recommendations for the CVD risk management for patients with rheumatoid arthritis and other forms of inflammatory joint diseases ${ }^{18}$. There are a set of overarching principles 
formulated, one of which states that the increased risk to develop CVD may apply to patients with psoriatic arthritis (PsA) and ankylosing spondylitis (AS) as well. In addition, patients with gout are long ago known to bare higher $\mathrm{CV}$ risk, taking into account that these patients are often known with metabolic syndrome that in turn is associated with higher CV risk. Taken together, these facts give a strong signal that an optimal CV risk management (CVRM) should become a mandatory part of the therapeutic workout of every patient with one of these chronic inflammatory conditions. Unfortunately, there are still some obstacles to overcome, which make the implementation of CVRM for these patients difficult to accomplish in the daily practice.

\section{I Cardiovascular risk calculators}

The identification of patients in the high-risk category forms the basis of a successful CVD prevention. In order to do that, CV risk calculators should be used, such as SCORE, Framingham or QRisk ${ }^{3}$. Yet, their usefulness in RA patients is limited and could lead sometimes to erroneous results: often an underestimation of the CV risk. One explanation for this could reside in the fact that the chronic inflammation in RA might accelerate the development of atherosclerosis and perhaps of the unstable plaques as well, which in turn might expedite the occurrence of an acute CV event. This might explain why young RA women have relatively higher rates of $C V$ events, although their initially predicted risk was very low. This leads to a mismatch between the predicted and observed CV risk ${ }^{19}$. It is not known yet if the traditional CV risk factors should have another weight in RA as compared to no-RA population. The attempt to adapt the current algorithms to fit better RA population is not easy neither always possible ${ }^{20}$. Therefore, EULAR recommends the use of the I.5 multiplying factor to the original SCORE result when calculating the risk in RA patients ${ }^{18}$. The 1.5 multiplying factor seems arbitrary but very practical in the same time, as long as the development and validation of a good RA-specific CV risk algorithm is still missing.

Finally, the present risk calculators are mainly used to quantify the CV risk for individuals aged between 40 and 70 years old. This might lead to problematic situations in the daily practice especially when rheumatologists and/or GPs should give advise to patients younger than 40 years on the CVRM issues. Therefo$\mathrm{re}$, the present recommendation is to evaluate these cases on individual CV-risk level and formulate the most reasonably advice accordingly.

\subsection{Lifestyle modification}

It is very important to realize that in the most of the cases a good CVRM would be constrained to just the following of good lifestyle recommendations. Firstly, patients should give-up smoking. Of note, quitting smoking positively impacts the CV risk but might also improve RA prognosis as well ${ }^{21}$. Cigarette smoking is strongly associated with the development of RA (especially in patients baring the shared-epitope) and may diminish the effects of therapy with TNF-alpha inhibitors as well ${ }^{22}$.

Secondly, physical activity should be encouraged in patients with RA, not just for the positive effects on the aerobic capacity but also for the improvement of the muscles' and joints' pain of degenerative and/or tendomyogen origin, which often co-exist with the other RA-related symptoms in these patients. The impact of regular physical activity on CV risk in RA has been often underestimated and is not so good evaluated so far. The lower level of physical capacity in RA, due to the disease-related pain level, has been suggested to have an important contribution to the total CV risk in these patients ${ }^{23}$. It is therefore of crucial importance for both CV as well as RA outcomes to stimulate physical activity in every RA patient.

Finally, overweight is often present in RA patients and crucially contributes to the development of hyperinsulinemia and diabetes, which in turn favor the occurrence of CVD. The accumulation of fat in the adipocytes leads locally to a low-grade inflammatory status and systemically to an increased level of adipokines and cytokines (such as leptin, adiponectin, TNF etc), some of them with important pro-inflammatory effects ${ }^{24}$. Given the association between cartilage damage and overweight, these results suggests that loosing weight and a balanced diet would positively impact both CV risk as well as RA-symptoms. It is desirable that all these recommendations regarding lifestyle changes should be implemented as optimal as possible in the daily practice. This is yet dependent on local and national protocols and regulations. Ideally, this task might be assigned to the GPs or other specialized health care providers (e.g. physiotherapist, dietician etc.), which could guide the patients referred also by the specialists based in hospitals (rheumatologists, cardiologists, internists, etc.).

\subsection{Drugs' therapy}

As already mentioned above, lifestyle changes are sufficient to lower CV risk at the desired level in the most of the RA patients. Yet, in some of these pati- 
ents therapy with drugs further needed in order to lower cholesterol and/or blood pressure levels at the target values. When looking at the cholesterol lowering therapy in the context of RA, several aspects are important to be considered. Firstly, statins have been previously indicated to poses anti-inflammatory effects as well. In a double-blind placebo controlled study, therapy of RA patients with atorvastatin was followed by lower inflammatory status and disease activity as compared to placebo, whereas similar sideeffects have been reported in both groups ${ }^{25}$. Secondly, the administration of atorvastatin to RA patients with overt CVD in a primary prevention setting has led to a lower incidence of CVD (I.6\%) as compared to placebo (2.4\%): HR 0.66 (95\% BI $0.39-\mathrm{I} .1 \mathrm{I})^{26}$. This difference has not reached statistical significance, probably due to the fact that the study had to be terminated earlier than initially designed because of (insufficient) power issues (number incident CVD lower than initially predicted). Finally, the hypothesis that hypercholesterolemia might actively be involved in the pathogenesis of RA and autoimmunity has been recently tested and the results presented during the 2020 EULAR Congress $^{27}$. This double-blind placebo controlled RCT (the STAPRA trial) investigated if daily administration of $40 \mathrm{mg}$ atorvastatin could prevent the development of RA in a group of Dutch individuals with a high-risk for RA (namely pre-RA individuals with anti-CCP positivity and joints pain without effusion - thus not yet arthritis). After a mean followed-up of 18 months, arthritis seemed to occur earlier (4 months vs. 6 months) and more often ( $26 \%$ vs. $19 \%$ ) in the placebo group as compared with atorvastatin users. Unfortunately, also in this study the authors confronted themselves with a lack of power, as they failed to reach the initially planed number of individuals that have to be included. Therefore, the differences between the groups lack statistical significance. Despite the fact that the antiinflammatory effects of statins are reasonably proved so far, their additional value in RA is still arguable by patients who benefit from an optimal anti-rheumatic therapy (using DMARDs) and have an adequate lifestyle. In this light, it is worth mentioning that statins may also have some side-effects including muscle pain and could be diabetogenic, both of important in the context of CVD and RA.

With respect to anti-hypertensive medication, it is worth mentioning perhaps that in the eighties there were a number of studies investigating the anti-rheumatic effects of angiotensin converting enzyme (ACE) inhibitors. These studies have been recently reviewed by our group ${ }^{28}$ and suggest that especially captopril bared important anti-inflammatory effects, most probably due to its similarities with D-penicillamine, a well-known anti-inflammatory drug. Of note, although AT-2 antagonists (ARBs) have not been directly investigated so far in the context of RA, they might theoretically have beneficial anti-inflammatory effects in this group of patients. This could be due to the ARBs blockade of multiple pro-inflammatory effects that follow after stimulation of AT-2 type I receptor, including higher pro-inflammatory cytokines production, activation of T-helper I (ThI) and ThI7 cells, suppression of $T$ regulatory (Treg) cells, activation of monocytes and dendritic cells etc ${ }^{29}$. Future studies are needed to further test hypothesis. Until that time, based on the present literature data, one can cautiously advise the preferential use of ARBs and/or ACEi as first line antihypertensive therapy in patients with RA and concomitant hypertensive.

Finally, one should not forget to consider the CV impact of various anti-rheumatic medications. Longterm therapy with high dosages of corticosteroids and/or the most of the non-steroid anti-inflammatory drugs (NSAIDs) is usually followed by an increased risk to develop CV events. Naproxen and more recently celecoxib $^{30}$ are likely to have a better $\mathrm{CV}$ profile, but caution should be taken also when RA patients are using these drugs and as a general rule, their use should be limited to on demand practice. On the other hand, the use of disease modifying anti-rheumatic drugs (DMARDs) is mostly associated with a favorable effect on CVD. Therapy with DMARDs lowers systemic inflammation and improves the anti-atherogenic capacity of HDL-cholesterol ${ }^{10,15}$. When RA patients achieve remission, the dosage of DMARDs is tapered in an attempt to reduce the chance of side-effects (e.g. infections) as well as to decrease the costs. Of note, the influence DMARDs tapering would have on CVD endpoints is not known yet and this crucial question should be further investigated in future studies.

\subsection{Implementation of CVRM}

The EULAR recommendations for CVRM in RA patients and patients with other inflammatory joint disorders stipulate in one of the overarching principles that the rheumatologist should be responsible for the initiation of CVRM in these patients ${ }^{18}$. However, the rheumatologist alone can not be responsible for the whole CVRM, as some patients would require drug therapy in order to lower their cholesterol and/or blood pressure levels, treatments that do not belong 
to the area of expertise of rheumatologists. Therefore, it is important to realize that CVRM by rheumatic patients needs a multi-disciplinary approach, involving all other medical specialists dealing with different aspects of CVRM, including cardiologists, internists and GPs. In addition, RA patients should be also appropriately informed over the various aspects of cardiovascular aspects in their disease, the importance of both lifestyle changes as well as of keeping their disease activity and inflammation as low as possible by appropriately using their anti-rheumatic medication. Screening for CV risk factors shoul ${ }^{31}$. The measurement of total cholesterol and blood pressure should be performed during a period of lower disease activity and low systemic inflammation to avoid the lipid paradox and thus an underestimation of the 10 -year CV risk. Screening for asymptomatic atherosclerotic plaques by use of carotid ultrasound of coronary artery calcium scores (using computed tomography) may be considered as part of risk evaluation in patients with RA, especially in those categorized as having a low/intermediate risk according to the SCORE algorithm.

Organizing CVRM for RA patients is quite complex. Several factors might play an important role in determining which way would help the most in order to achieve the best result, namely a significant decrease of CV risk in these patients, translated into a significant decrease in incident acute $C V$ events, lower costs in the healthcare system ${ }^{32}$ and better prognosis. These factors are likely to be population and/or country-specific factors such as socio-economic status, national health care policies and reimbursements regulations. In the Netherlands several models are already implemented in the daily practice. In some regions patients are screened by a rheumatologist on the outpatient clinic, yet the follow-up would take place in the general practitioner's (GP) office ${ }^{3}$. In other places the GPs are fully responsible for the CVRM, the only task for the rheumatologist is to ask the GP to initiate $\mathrm{CVRM}^{33}$. The first Dutch model is similar with the model recently presented by Primdahl et al in a Danish population ${ }^{34}$. Interestingly, in Oslo, Norway, a cardio-rheuma clinic has been established in which cardiologists coordinate both processes of screening as well as follow-up until patients lower their CV risk factors to the target values and are thereafter referred to their GPs ${ }^{35}$. This approach might give some advantages by securing adequate therapy, yet organizing and financing such clinics might remain elusive for many rheumatologic centers worldwide.

\section{CONCLUSION}

Rheumatoid arthritis is an independent CV risk factor and the higher CVD burden in these patients is likely to be due to both traditional CV risk factors as well as RA/inflammation-related factors. Early initiation of the anti-rheumatic therapy following the treat-to-target (T2T) protocols, together with appropriate lifestyle changes are able to considerably decrease the CVrisk in a large majority of these patients. Nevertheless, some high CV-risk patients would need to be treated with cholesterol lowering and/or anti-hypertensive drugs. The initiation and follow-up of the therapy with these drugs should be the task of a GP, cardiologist or internist. Therefore, CVRM in RA needs a multi-disciplinary approach, with local solutions emerging sometimes as the best serving the scope. The later should remain decreasing CVD in RAs, therefore improving the prognosis and the quality of life for these patients with a lifetime chronic disorder.

\section{Conflict of interest: none declared.}

\section{References}

I. Dougados M, Soubrier M, Antunez A, Balint P, Balsa A, Buch $M H$, Casado G, Detert J, El-Zorkany B, Emery P, Hajjaj-Hassouni N, Harigai M, Luo SF, Kurucz R, Maciel G, Mola EM, Montecucco CM, McInnes I, Radner H, Smolen JS, Song YW, Vonkeman HE, Winthrop K, Kay J. Prevalence of comorbidities in rheumatoid arthritis and evaluation of their monitoring: results of an international, cross-sectional study (COMORA). Ann Rheum Dis 2014; 73:62-8.

2. Avina-Zubieta JA, Thomas J, Sadatsafavi M, Lehman AJ, Lacaille D. Risk of incident cardiovascular events in patients with rheumatoid arthritis: a meta-analysis of observational studies. Ann Rheum Dis 2012; 7I:I524-9.

3. van den Oever IAM, Heslinga M, Griep EN, Griep-Wentink HRM, Schotsman R, Cambach W, Dijkmans BAC, Smulders YM, Lems WF, Boers M, Voskuyl AE, Peters MJL, van Schaardenburg D, Nurmohamed MT. Cardiovascular risk management in rheumatoid arthritis patients still suboptimal: the Implementation of Cardiovascular Risk Management in Rheumatoid Arthritis project. Rheumatology (Oxford) 2017; 56:1472-8.

4. Lindhardsen J, Ahlehoff $O$, Gislason GH, Madsen OR, Olesen JB, Torp-Pedersen C, Hansen PR. The risk of myocardial infarction in rheumatoid arthritis and diabetes mellitus: a Danish nationwide cohort study. Ann Rheum Dis 20I I; 70:929-34.

5. Arida A, Protogerou AD, Kitas GD, Sfikakis PP. Systemic Inflammatory Response and Atherosclerosis: The Paradigm of Chronic Inflammatory Rheumatic Diseases. Int J Mol Sci 2018; 19: pii: El890.

6. Fent GJ, Greenwood JP, Plein S, Buch MH. The role of non-invasive cardiovascular imaging in the assessment of cardiovascular risk in rheumatoid arthritis: where we are and where we need to be. Ann Rheum Dis 2017; 76:1 169-75.

7. Corrao S, Messina S, Pistone G, Calvo L, Scaglione R, Licata G. Heart involvement in rheumatoid arthritis: systematic review and metaanalysis. Int J Cardiol 2013; 167:203 I-8.

8. Amigues I, Russo C, Giles JT, Tugcu A, Weinberg R, Bokhari S, Bathon JM. Myocardial Microvascular Dysfunction in Rheumatoid Arthritis: Quantitation by I3N-Ammonia Positron Emission Tomography/Computed Tomography. Circ Cardiovasc Imaging 2019; I2:e007495. 
9. Van Doornum S, Brand C, King B, Sundararajan V. Increased case fatality rates following a first acute cardiovascular event in patients with rheumatoid arthritis. Arthritis Rheum 2006; 54:206I-8.

10. Arts EE, Fransen J, Den Broeder AA, van Riel PLCM, Popa CD. Low disease activity (DAS28 3.2 ) reduces the risk of first cardiovascular event in rheumatoid arthritis: a time-dependent Cox regression analysis in a large cohort study. Ann Rheum Dis 2017; 76:1693-9.

II. Crowson CS, Rollefstad S, Ikdahl E, Kitas GD, van Riel PLCM, Gabriel SE, Matteson EL, Kvien TK, Douglas K, Sandoo A, Arts E, Wållberg-Jonsson S, Innala L, Karpouzas G, Dessein PH, Tsang L, El-Gabalawy H, Hitchon C, Ramos VP, Yáñez IC, Sfikakis PP, Zampeli E, Gonzalez-Gay MA, Corrales A, Laar MV, Vonkeman HE, Meek I, Semb AG; A Trans-Atlantic Cardiovascular Consortium for Rheumatoid Arthritis (ATACC-RA). Impact of risk factors associated with cardiovascular outcomes in patients with rheumatoid arthritis. Ann Rheum Dis 2018; 77:48-54.

12. Francisco V, Ruiz-Fernandez C, Pino J, Mera A, Gonzalez-Gay MA, Gomez R, Lago F, Mobasheri A, Gualillo O. Adipokines: linking metabolic syndrome, the immune system, and arthritis diseases. Biochem Pharmacol 2019; 165:196-206.

13. Johnsson H, Panarelli M, Cameron A, Sattar N. Analysis and modeling of cholesterol and high-density lipoprotein cholesterol changes across the range of C-reactive protein levels in clinical practice as an aid to better understanding of inflammation-lipid interactions. Ann Rheum Dis 2012; 73:1495-9.

14. Popa C, van Tits LJ, Barrera P, Lemmers HL, van den Hoogen FH, van Riel PL, Radstake TR, Netea MG, Roest M, Stalenhoef AF. Antiinflammatory therapy with tumour necrosis factor alpha inhibitors improves high-density lipoprotein cholesterol antioxidative capacity in rheumatoid arthritis patients. Ann Rheum Dis 2009; 68:868-72.

15. Charles-Schoeman C, Gugiu GB, Ge H, Shahbazian A, Lee YY, Wang $X$, Furst DE, Rananath VK, Maldonado M, Lee T, Reddy ST. Remodeling of the HDL proteome with treatment response to abatacept or adalimumab in the AMPLE trial of patients with rheumatoid arthritis. Atherosclerosis 2018; 275:107-14.

16. Gonzalez A, Maradit Kremers H, Crowson CS, Ballman KV, Roger VL, Jacobsen SJ, O'Fallon WM, Gabriel SE. Do cardiovascular risk factors confer the same risk for cardiovascular outcomes in rheumatoid arthritis patients as in non-rheumatoid arthritis patients? Ann Rheum Dis 2008; 67:64-9.

17. Toms TE, Panoulas VF, Douglas KM, Griffiths H, Sattar N, Smith JP, Symmons DP, Nightingale P, Metsios GS, Kitas GD. Statin use in rheumatoid arthritis in relation to actual cardiovascular risk: evidence for substantial undertreatment of lipid-associated cardiovascular risk? Ann Rheum Dis 2010; 69:683-8.

18. Agca R, Heslinga SC, Rollefstad S Heslinga M, Mclnnes IB, Peters MJ, Kvien TK, Dougados M, Radner H, Atzeni F, Primdahl J, Södergren A, Wallberg Jonsson S, van Rompay J, Zabalan C, Pedersen TR, Jacobsson L, de Vlam K, Gonzalez-Gay MA, Semb AG, Kitas GD, Smulders YM, Szekanecz Z, Sattar N, Symmons DP, Nurmohamed MT. EULAR recommendations for cardiovascular disease risk management in patients with rheumatoid arthritis and other forms of inflammatory joint disorders: 2015/2016 update. Ann Rheum Dis 2017; 76:17-28.

19. Fransen J, Kazemi-Bajestani SM, Bredie SJ, Popa CD. Rheumatoid Arthritis Disadvantages Younger Patients for Cardiovascular Diseases: A Meta-Analysis. PLoS One 2016; I I:e0157360.

20. Arts EE, Popa CD, den Broeder AA, Donders R, Sandoo A, Toms T, Rollefstad S, Ikdahl E, Semb AG, Kitas GD, van Riel PL, Fransen J. Prediction of cardiovascular risk in rheumatoid arthritis: performance of original and adapted SCORE algorithms. Ann Rheum Dis 2016; 75:674-80.

21. Rojas-Serrano J, Pérez LL, Garciá CG, Moctezuma F, ÁlvarezHernández E, Vázquez-Mellado J, Montiel JL, Burgos-Vargas R. Current smoking status is associated to a non-ACR 50 response in early rheumatoid arthritis. A cohort study. Clin Rheumatol 201 I; 30:1589-93.
22. Hyrich KL, Watson KD, Silman AJ, Symmons DP; British Society for Rheumatology Biologics Register. Rheumatology (Oxford) 2006; 45: 1558-65.

23. Metsios GS, Moe RH, van der Esch M, van Zanten JJCSV, Fenton SAM, Koutedakis Y, Vitalis P, Kennedy N, Brodin N, Bostrom C, Swinnen TW, Tzika K, Niedermann K, Nikiphorou E, Fragoulis GE, Vlieland TPVM, Van den Ende CHM, Kitas GD; IMPACT-RMD Consortium. The effects of exercise on cardiovascular disease risk factors and cardiovascular physiology in rheumatoid arthritis. Rheumatol Int 2020; 40:347-357

24. Scheja L, Heeren J. The endocrine function of adipose tissue in helath and cardiometabolic disease. Nat Rev Endocrinol 2019; 15:507524.

25. McCarey DW, Mclnnes IB, Madhok R, Hampson R, Scherbakov O, Ford I, Capell HA, Sattar N. Trial of Atorvastatin in Rheumatoid Arthritis (TARA): double-blind, randomised placebo-controlled trial. Lancet 2004; 363:2015-2I.

26. Kitas GD, Nightingale P, Armitage J, Sattar N, Belch JJF, Symmons DPM; TRACE RA Consortium. A Multicenter, Randomized, Placebo-Controlled Trial of Atorvastatin for the Primary Prevention of Cardiovascular Events in Patients With Rheumatoid Arthritis. Arthritis Rheumatol 2019; 71:1437-49.

27. van Boheemen L, Turk SA, van Beers - Tas M, Bos WH, Marsman D, Griep EN, Starmans M, Popa CD, van Sijl AM, Boers M, Nurmohamed M, van Schaardenburg D. AB0230 Statins to prevent rheumatoid arthritis: inconclusive results of the STAPRA trial http://dx.doi. org/l0.I I36/annrheumdis-2020-eular.2805

28. Popa CD, van Riel PL. The use of captopril in rheumatoid arthritis: combining treatment targets! Can J Cardiol 2013; 29:639.el3

29. Chang Y, Wei W. Angiotensin II in inflammation, immunity and rheumatoid arthritis. Clin Exp Immunol. 20I5;I79(2):137-I45. doi: I0.1 I I I/cei. 12467

30. Nissen SE, Yeomans ND, Solomon DH, Lüscher TF. Libby P, Husn ME, Graham DY, Borer JS, Wisniewski LM, Wolski KE, Wang Q, Menon V, Ruschitzka F, Gaffney M, Beckerman B, Berger MF, Bao W, Lincoff AM; PRECISION Trial Investigators. Cardiovascular safety of celecoxib, naproxen or ibuprofen for arthritis. N Engl J Med 2016; 375:2519-29.

31. Piepoli MF, Hoes AW, Agewall S, Albus C, Brotons C, Catapano AL, Cooney MT, Corrà U, Cosyns B, Deaton C, Graham I, Hall MS, Hobbs FDR, Løchen ML, Löllgen H, Marques-Vidal P, Perk J, Prescott E, Redon J, Richter DJ, Sattar N, Smulders Y, Tiberi M, van der Worp HB, van Dis I, Verschuren WMM, Binno S; ESC Scientific Document Group. 2016 European Guidelines on cardiovascular disease prevention in clinical practice: The Sixth Joint Task Force of the European Society of Cardiology and Other Societies on Cardiovascular Disease Prevention in Clinical Practice (constituted by representatives of 10 societies and by invited experts): developed with the special contribution of the European Association for Cardiovascular Prevention \& Rehabilitation (EACPR). Eur Heart J 2016; 37:23 I5-8I.

32. Kievit W, Maurits JS, Arts EE, van Riel PL, Fransen J, Popa CD. Costeffectiveness of cardiovascular screening in patients with rheumatoid arthritis. Arthritis Care Res 2017; 69:175-182.

33. Weijers JM, Rongen-van Dartel SAA, Hoevenaars DMGMF, Rubens $M$, Hulscher MEJL, van Riel PLCM. Implementation of the EULAR cardiovascular risk management guideline in patients with rheumatoid arthritis: results of a successful collaboration between primary and secondary care. Rheum Ann Dis 2018; 77:480-3.

34. Primdahl J, Clausen J, Hørslev-Petersen K. Results from systematic screening for cardiovascular risk in outpatients with rheumatoid arthritis in accordance with the EULAR recommendations. Ann Rheum Dis. 2013; 72:177I-6.

35. Rollefstad S, Kvien TK, Holme I, Eirheim AS, Pedersen TR, Semb AG. Treatment to lipid targets in patients with inflammatory joint diseases in a preventive cardio-rheuma clinic. Ann Rheum Dis. 2013; 72:1968-74. 